\title{
SSC Collider Dipole Cryostat
}

\author{
Thomas H. Nicol \\ Fermi National Accelerator Laboratory \\ P.O. Box 500 \\ Batavia, IL 60510 \\ USA
}

\section{INTRODUCTION}

The design of the Superconducting Super Collider (SSC) required the construction of 7,680 superconducting dipole or bending magnets, each 17 meters long, 1,356 quadrupoles or focusing magnets, each 3.3 meters long as well as several special magnets, spool pieces, and other hardware. The entire accelerator was to be housed in an 83 kilometer-long underground tunnel. [1]

Fermilab was involved in the design and production of cryostats for all prototype SSC dipole magnets built beginning in 1986. Late in 1989 a fundamental change in the dipole coil design; increasing the physical aperture from $40 \mathrm{~mm}$ to $50 \mathrm{~mm}$, resulted in the need to redesign the dipole cryostat. The larger aperture gave rise to an increase in diameter of the overall cold mass assembly of approximately $25 \%$ and a weight increase of approximately $50 \%$ both of which impact the cryostat design significantly.

Cryostat designs for superconducting magnets are largely driven by thermal and structural considerations. Designers must continually be cognizant of the heat load to the helium system and of the structural loads imposed on the cryostat systems from static weight, shipping and handling, quench loads, and ambient ground motion. These two considerations are generally at odds with one another. Low heat load implies a minimum of structural material conducting heat from the environment. Sound structural design implies material with sufficient strength to resist both static and dynamic forces.

This chapter summarizes the results of the $50 \mathrm{~mm}$ collider dipole cryostat design effort. Thermal and structural aspects of the design of each of the major cryostat systems will be described in detail. The $40 \mathrm{~mm}$ dipole cryostat purposely served as the starting point for this design work. Wherever possible, development work on that and other similar cryostats was borrowed in order to take advantage of proven technology. References to the $40 \mathrm{~mm}$ cryostat will be made for comparison wherever appropriate. Each of the cryostat systems will be addressed in turn; vacuum vessel, $80 \mathrm{~K}$ and $20 \mathrm{~K}$ thermal radiation shields, multilayer insulation (MLI), cryogenic piping, suspension system, and magnet interconnect. 
To begin the design process, one needs a good handle on the pertinent allowable heat loads to each thermal station as well as a good definition of the structural environment to which the magnet will be subjected. Given the large number of magnets, even a small heat load, especially to $4.5 \mathrm{~K}$, could result in a significant increase in the overall capacity of the cryogenic plants needed. Table 1 summarizes the thermal and structural design criteria for the $50 \mathrm{~mm}$ dipole which affect the cryostat design. Figure 1 illustrates a cross section through the $50 \mathrm{~mm}$ cryostat. [2, 3]

\begin{tabular}{|c|c|c|c|}
\hline & \multicolumn{2}{|c|}{ Table 1. Thermal and Structural Design Criteria } & \\
\hline & $4.5 \mathrm{~K}$ & $20 \mathrm{~K}$ & $80 \mathrm{~K}$ \\
\hline \multicolumn{4}{|l|}{ Static heat loads } \\
\hline Infrared & $0.053 \mathrm{~W}$ & $2.335 \mathrm{~W}$ & $19.1 \mathrm{~W}$ \\
\hline Support conduction & $0.160 \mathrm{~W}$ & $2.400 \mathrm{~W}$ & $15.8 \mathrm{~W}$ \\
\hline Interconnect & $0.150 \mathrm{~W}$ & $0.320 \mathrm{~W}$ & $2.1 \mathrm{~W}$ \\
\hline Total static & $0.363 \mathrm{~W}$ & $5.055 \mathrm{~W}$ & $37.0 \mathrm{~W}$ \\
\hline \multicolumn{4}{|l|}{ Dynamic heat loads } \\
\hline Synchrotron radiation & $2.169 \mathrm{~W}$ & & \\
\hline Splice heating & $0.140 \mathrm{~W}$ & & \\
\hline Beam microwave & $0.195 \mathrm{~W}$ & & \\
\hline Beam gas & $0.136 \mathrm{~W}$ & & \\
\hline Total dynamic & $2.640 \mathrm{~W}$ & & \\
\hline Total dipole & $3.003 \mathrm{~W}$ & $5.055 \mathrm{~W}$ & $37.0 \mathrm{~W}$ \\
\hline \multicolumn{4}{|l|}{ Structural load summary } \\
\hline Cold mass weight & & $11,360 \mathrm{~kg}$ & \\
\hline \multirow[t]{3}{*}{ Shipping and handling } & & $2.0 \mathrm{~g}$ & vertical \\
\hline & & $1.5 \mathrm{~g}$ & Axial \\
\hline & & $1.0 \mathrm{~g}$ & lateral \\
\hline
\end{tabular}




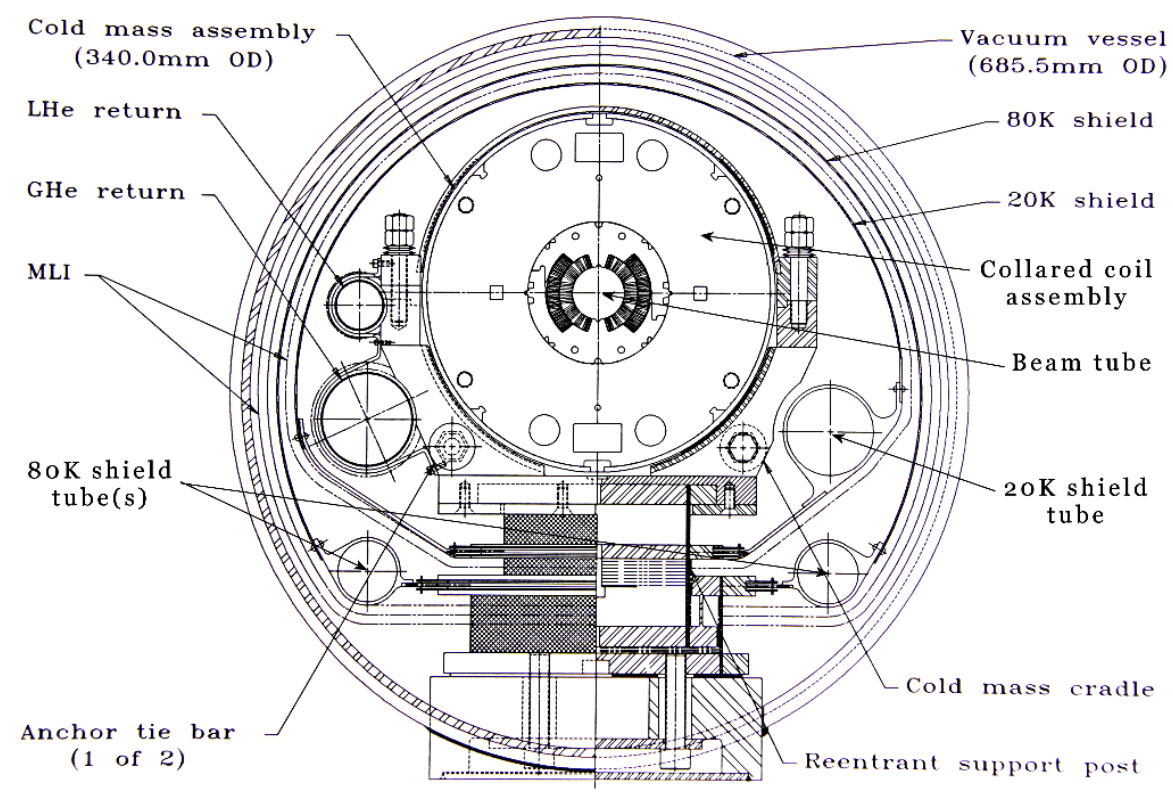

Figure 1. SSC 50mm Collider Dipole Cryostat - Cross Section

\section{VACUUM VESSEL}

The vacuum vessel was the outermost cryostat component and served to contain the insulating vacuum. In addition, it functioned as the major structural element to which all other systems were ultimately attached to the accelerator tunnel floor. Furthermore, it served as a pressure containment vessel in the event of a failure in an internal cryogen line. The vessel was a carbon steel cylinder $685.5 \mathrm{~mm}$ OD, 7.92 $\mathrm{mm}$ wall with an overall length of $14922.5 \mathrm{~mm}$.

The vessel had five penetrations at which the internal cold mass supports were attached. The internal supports were positioned to minimize the deflection of the cold assembly due to its own weight and were spaced on $3179.76 \mathrm{~mm}$ centers starting at the center of the magnet. Two external supports served to tie the vessel to the tunnel floor. The external supports were spaced to minimize the deflection of the vacuum vessel due to its own weight and to the weight of the internal components. They were located $4154.17 \mathrm{~mm}$ on either side of center. 
The $7.92 \mathrm{~mm}$ wall of the vessel was not sufficient to transfer suspension system loads to ground immediately around the internal support locations. At these positions a $19.05 \mathrm{~mm}$ thick, $559 \mathrm{~mm}$ long reinforcement transferred internally generated loads, primarily from shipping and handling, from the magnet support system to the vacuum vessel. Figure 2 illustrates the major features of the vacuum vessel and notes applicable dimensions. The vacuum vessel material was low carbon steel. Ordinarily one would like to use a material with greater fracture toughness in the event of a major cryogen spill inside the cryostat, however, cost mandated a more readily available material. In addition, failure analysis indicated that a high fracture toughness material was not required. [2, 3]

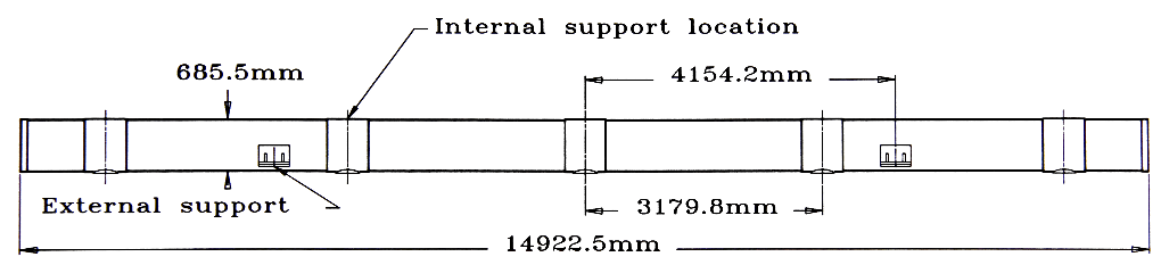

Figure 2. SSC 50mm Collider Dipole Vacuum Vessel Layout

Referring only to drawings, it's easy to lose sight of the scale of these magnets. Figure 3 shows a complete dipole magnet being transported within the Fermilab site on a full-length tractor-trailer.

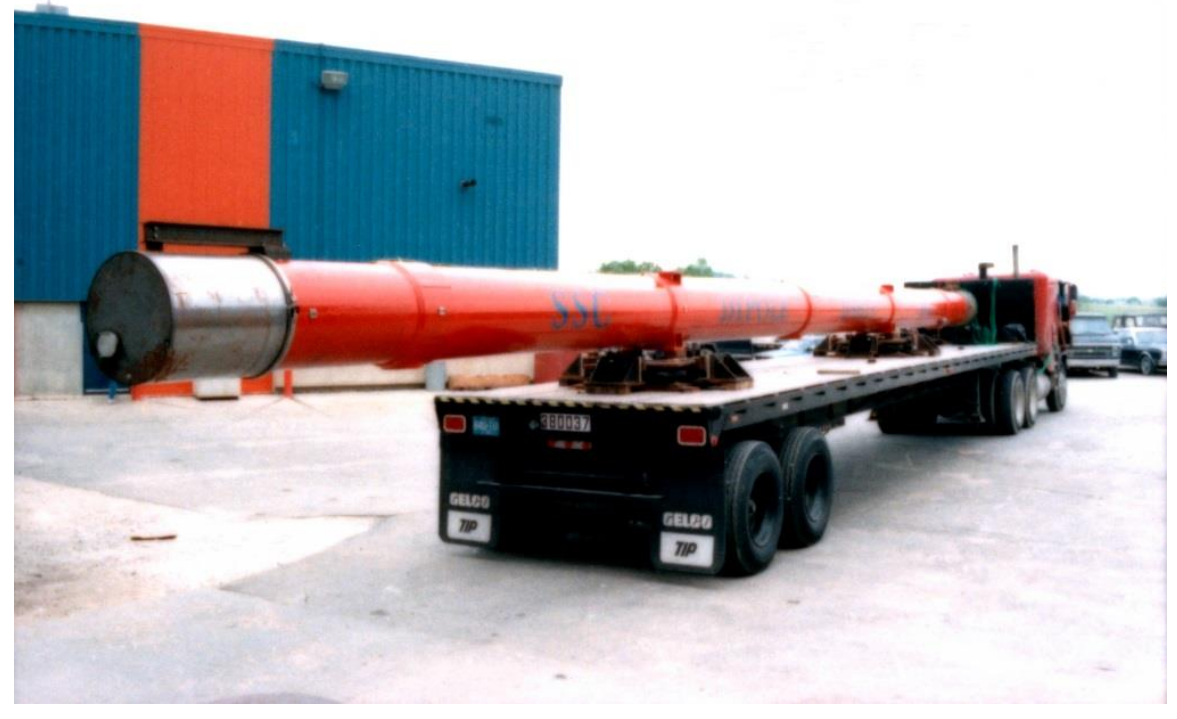

Figure 3. SSC 50mm Collider Dipole Complete Magnet 


\section{THERMAL RADIATION SHIELDS}

In order to minimize thermal radiation heat load to the $4.5 \mathrm{~K}$ magnet, the cryostat used two thermal radiation shields. The outer shield was cooled by $\mathrm{LN}_{2}$ and operated nominally at $80 \mathrm{~K}$. The inner shield was cooled by helium gas returning to the refrigerator and operated nominally at $20 \mathrm{~K}$. Each shield was cooled by discrete pipes connected to formed shells which totally encompassed the internal cold assembly. The $20 \mathrm{~K}$ shield used a single extrusion attached to the shell. The $80 \mathrm{~K}$ shield used two; one serving as the shield supply, the other as the return. This scheme required that the shells have high thermal conductivity to minimize thermal gradients around their circumference. Copper and aluminum are the materials of choice for this application. Thermal analyses on both shields were performed using both materials. The results from these analyses indicated there is no significant difference in the thermal performance of either shield between these two materials. Material cost dictated the ultimate material choice. Copper and aluminum are approximately the same cost per unit weight, however, with a density over three times that of aluminum, the use of copper as the shield material would have resulted in an assembly cost three times higher than an aluminum shield. The selected material for both $80 \mathrm{~K}$ and $20 \mathrm{~K}$ shields was $6061-\mathrm{T} 6$ aluminum, $1.59 \mathrm{~mm}$ thick. The shields were segmented along their length to minimize the effect of bowing during cooldown caused by the asymmetry of the cooling tubes with respect to the shield shells. The thermal shields are shown in figure 1 . The lower half of a $20 \mathrm{~K}$ thermal shield assembly is shown in figure 4. [2, 3]

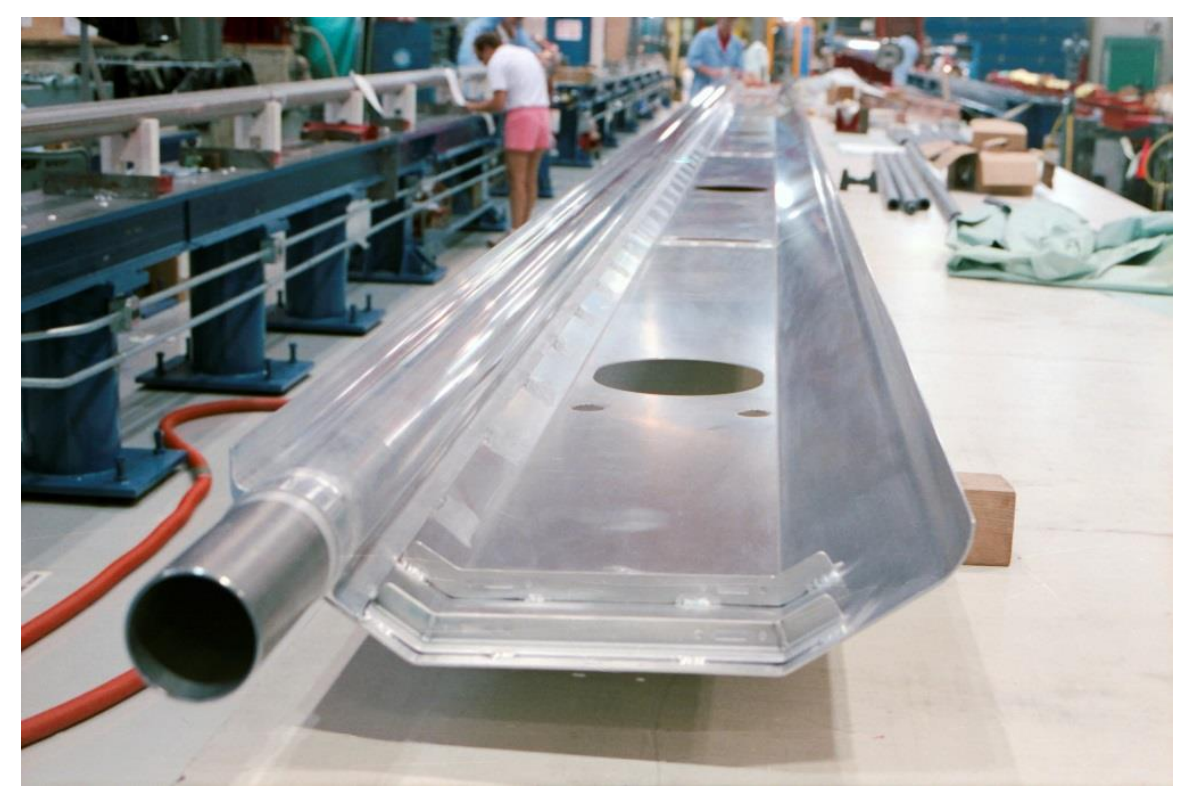


Figure 4. Lower Half of the $20 \mathrm{~K}$ Thermal Shield Assembly

\section{MULTILAYER INSULATION}

The design requirements for the thermal insulation system in the SSC dipole cryostat dictated that heat load from thermal radiation and residual gas conduction be limited to the values listed in Table 1. Essential to meeting these requirements was an insulation system design that addressed transient conditions through high layer density for improved gas conduction shielding, had sufficient mass and heat capacity to reduce the effects of thermal transients, and was comprised of materials suitable for extended use in a high radiation environment. Finally, the system design was such that fabrication and installation techniques guaranteed consistent thermal performance throughout the entire accelerator.

The insulation system needed to have a mean apparent thermal conductivity of $0.76 \times 10^{-6} \mathrm{~W} / \mathrm{cm}-\mathrm{K}$ in order to meet the design heat load budget. This was achieved by using a multilayer insulation (MLI) system comprised of reflective layers of aluminized polyester separated by layers of spun-bonded polyester spacer. The reflective layers consisted of flat polyester film aluminized on both sides to a nominal thickness not less than 350 angstroms. The spacer layers consisted of randomlyoriented spun-bonded polyester fiber mats. The mean apparent thermal conductivity of an MLI blanket comprised of these materials was measured to be $0.52 \times 10^{-6}$ W/cm-K6,7. The MLI system for the SSC 50mm collider dipole cryostat consisted of full cryostat-length assemblies of MLI fabricated and installed as blankets on the $80 \mathrm{~K}$ and $20 \mathrm{~K}$ shields. [2, 3, 4]

The MLI system for the $80 \mathrm{~K}$ thermal shield consisted of two 32-reflective-layer blanket assemblies, for a total of 64 reflective layers. The stack height of each 32layer blanket was $8.86 \mathrm{~mm}$, with a mean layer density of 3.61 layers per $\mathrm{mm}$. The blanket design incorporated 32 reflective layers of double-aluminized polyethylene terephthalate (PET) film. The reflective layers were separated by single spacer layers of $0.10 \mathrm{~mm}$ spun-bonded PET material. Single layers of $0.23 \mathrm{~mm}$ spun-bonded PET covered the blanket top and bottom and served to position the polyester hook and loop fasteners at the blanket edges. The fasteners were affixed to the cover layers by sewing. A third $0.23 \mathrm{~mm}$ PET layer was located midway through the blanket assembly and separated the upper and lower 16 reflective layers of MLI. The multiple blanket layers were sewn together as an assembly along both edges of the blanket. Non-lubricated polyester thread was used in all sewing operations.

The MLI system for the $20 \mathrm{~K}$ thermal shield consisted of ten reflective layers of PET film aluminized with a nominal coating of 600 angstroms per side. The reflective layers were separated by three spacer layers of $0.1 \mathrm{~mm}$ spun-bonded PET ma- 
terial. Single layers of $0.23 \mathrm{~mm}$ spun-bonded PET covered the blanket top and bottom and served to position the polyester hook and loop fasteners at the blanket edges. The fasteners were attached to the cover layers by sewing. The multiple blanket layers were sewn together as an assembly along both edges of the blanket.

At each blanket edge, the upper MLI layers were sewn together from the upper cover layer through to the middle three layers with thread terminated in the three layers. The seam location was then incremented $7.62 \mathrm{~cm}$ laterally along the midlayer and the lower MLI layers were sewn together from the middle three layers through to the lower cover layer. Figure 5 shows a cross section of the $80 \mathrm{~K}$ MLI blanket.

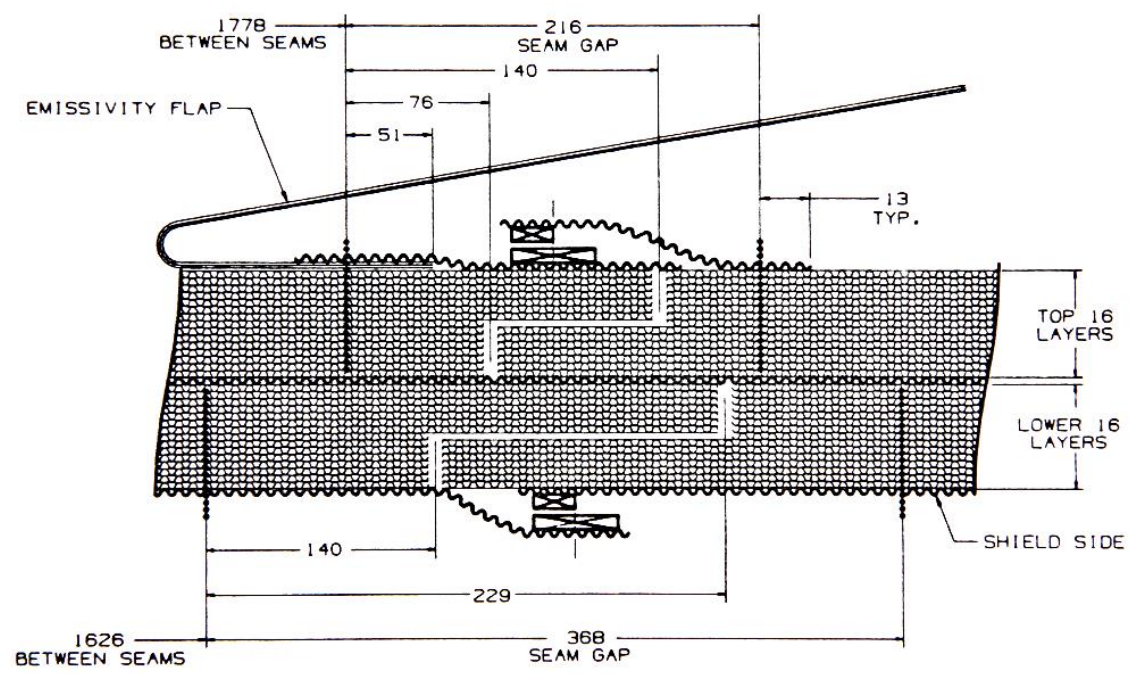

Figure 5. Cross Section through the $80 \mathrm{~K}$ MLI Blanket

To facilitate assembly and all the blankets required to support the SSC pre-production program, a system was devised to wrap and sew complete blanket assemblies. It consisted of a wheel with a width equal to the perimeter of the blankets and a circumference equal to their length. The reflector and spacer materials were fed off supply reels onto the wheel and the edges were sewn after wrapping the required number of layers was complete. Figure 6 shows the assembly wheel during the winding process. 


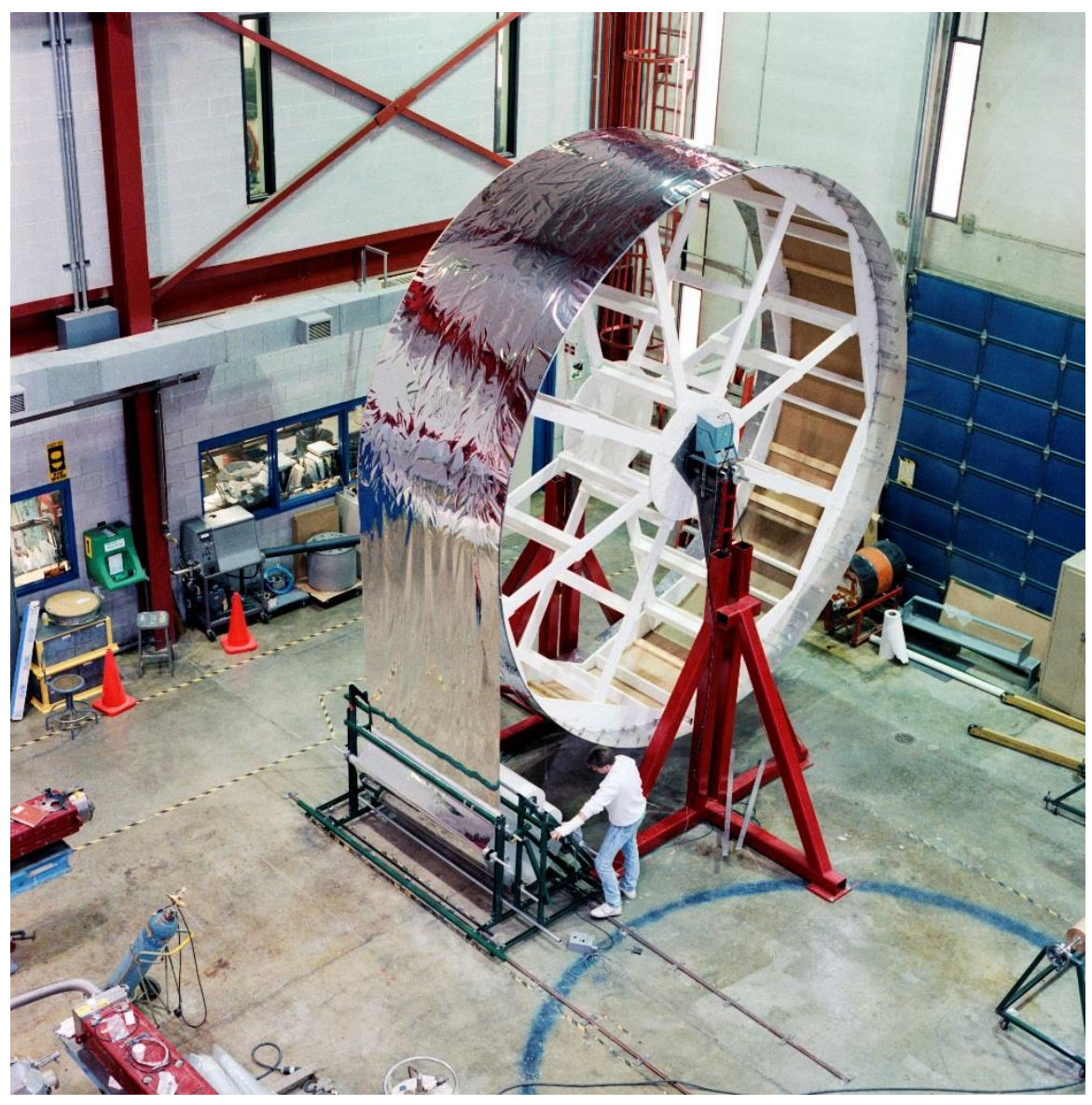

Figure 6. MLI Blanket Winding and Sewing Apparatus

\section{CRYOGENIC PIPING}

In addition to providing the necessary structural support and thermal insulation for the cold mass assembly, the cryostat served to contain the piping for all of the cryogenic services required for magnet and magnet system operation. All the cryogenic pipes are shown in figure 1 . Table 2 provides a summary of the pressure and flow parameters for each of these services. Table 3 lists the pipe sizes for each of the cryostat pipes. Each pipe was anchored at the center of the magnet assembly, and was free to slide axially at the remaining support points to allow for thermal contraction during cooldown.

Table 2. Cryogenic System Pressure and Flow Parameters

\begin{tabular}{|l|l|l|l|l|l|l|l|} 
System & $\mathrm{P}(\max )$ & Fluid & $\mathrm{P}($ oper $)$ & $\mathrm{v}$ & $\mathrm{T}$ & Flow & $\Delta \mathrm{P}$ \\
\hline
\end{tabular}




\begin{tabular}{|c|c|c|c|c|c|c|c|}
\hline & $(\mathrm{atm})$ & & $(\mathrm{atm})$ & $(\mathrm{cm} 3 / \mathrm{g})$ & $(\mathrm{K})$ & $(\mathrm{g} / \mathrm{s})$ & $(\mathrm{psi})$ \\
\hline $20 \mathrm{~K}$ shield & 18 & $\mathrm{He}$ & 2.5 & 163.4 & 20 & 100 & 0.016 \\
\hline $80 \mathrm{~K}$ shield & 18 & $\mathrm{LN} 2$ & 5.0 & 1.286 & 84 & 750 & 0.012 \\
\hline Single phase & 18 & $\mathrm{He}$ & 4.0 & 7.255 & 4.25 & 100 & 0.010 \\
\hline LHe return & 18 & $\mathrm{He}$ & 3.0 & 7.609 & 4.425 & 85.6 & 0.010 \\
\hline GHe return & 9 & $\mathrm{He}$ & 0.9 & 73.07 & 4.3 & 26.8 & 0.00053 \\
\hline Vac vessel & 2 & $\mathrm{He}$ & 0.0 & $\mathrm{na}$ & 300 & $\mathrm{na}$ & $\mathrm{na}$ \\
\hline
\end{tabular}

\begin{tabular}{|c|c|c|c|c|}
\hline \multicolumn{5}{|c|}{ Table 3. Cryostat Pipe Sizes } \\
\hline System & Pipe ID & Pipe OD & Flow area & Material \\
\hline & $(\mathrm{mm})$ & $(\mathrm{mm})$ & $\left(\mathrm{mm}^{2}\right)$ & \\
\hline 20 K shield & 82.55 & 88.90 & 5352 & Aluminum \\
\hline 80 K shield & 57.15 & 63.50 & $2565 \times 2$ & Aluminum \\
\hline LHe return & 45.14 & 47.62 & 1600 & Stainless steel \\
\hline GHe return & 86.41 & 88.90 & 5864 & Stainless steel \\
\hline
\end{tabular}

\section{SUSPENSION SYSTEM}

The suspension system in any superconducting magnet serves as the structural attachment for all cryostat systems to the vacuum vessel which in turn anchors them to the accelerator tunnel floor. Conventional suspension systems were effectively reinvented during early SSC magnet development. The intention in development of the $50 \mathrm{~mm}$ dipole cryostat was to take advantage of that earlier work tailoring it only for the revised thermal and structural design parameters. Schedule requirements for the redesign work did not allow continued suspension R\&D and, in fact, the thermal and structural performance of the $40 \mathrm{~mm}$ design did not indicate it to be necessary. $[2,3,5,6,7]$

Using the thermal and structural parameters outlined in table 1 the suspension system for the new design was extrapolated from its $40 \mathrm{~mm}$ counterpart. The emphasis was on meeting the allowed suspension system conduction heat load, satisfying the structural requirements, and maximizing the lateral suspension stiffness. This latter constraint is not explicitly defined in the design criteria but arose out of concerns during testing of $40 \mathrm{~mm}$ prototypes that the lateral natural frequency was too closely coupled with resonances found in an over the road shipping environment.

As shown in figure 7, the suspension system consisted of two major components; reentrant style support posts and anchor tie bars. There were five support posts located along the length of an SSC cold mass assembly spaced $3179.76 \mathrm{~mm}$ apart centered about the middle of the cold mass. Five being the number which limited the cold mass sag due to self-weight to the allowed $0.25 \mathrm{~mm}$. The support posts 
resisted vertical and lateral loads imposed during shipping and handling. The cold mass was allowed to slide axially with respect to all but the center post to allow for thermal contraction of the cold assembly during cooldown. This implied that, given no other restraint, the center support would need to resist axial loads. A single support was not capable of resisting this potential $1.5 \mathrm{~g}$ load. Using a special support at the center which could handle this load would have imposed inordinately high heat loads on the refrigeration system. Rather, a means was developed to distribute axial loads to all five supports without impacting the conduction heat load. Axial tie bars were used to connect the top of each support post to its neighbor(s). In this scheme, an axial load acted first at the center support and then distributed to all five supports.

The tie bars needed to be dimensionally stable when cooled from their assembly temperature of $300 \mathrm{~K}$ to their operating temperature of $4.5 \mathrm{~K}$, otherwise their contraction would impose high bending loads on the support posts. Uniaxial graphite fibers in an epoxy matrix provided the solution. This material is extremely stiff and yet exhibits virtually no change in length during cooldown. An elastic modulus of $82.5 \mathrm{GPa}$ can be achieved in such a composite even with relatively low modulus fibers.

The configuration of the support posts for the $50 \mathrm{~mm}$ cryostat is shown in figure 8. The outer composite tube was $2.16 \mathrm{~mm}$ thick and filament wound using S-glass in an epoxy matrix. The inner tube was $3.18 \mathrm{~mm}$ thick and filament wound using graphite fibers in an epoxy matrix. The ability of this design to use two different materials allowed each material to be used in its optimum temperature range. Table 4 provides a summary of the critical design and performance parameters of the 50 $\mathrm{mm}$ cryostat supports.

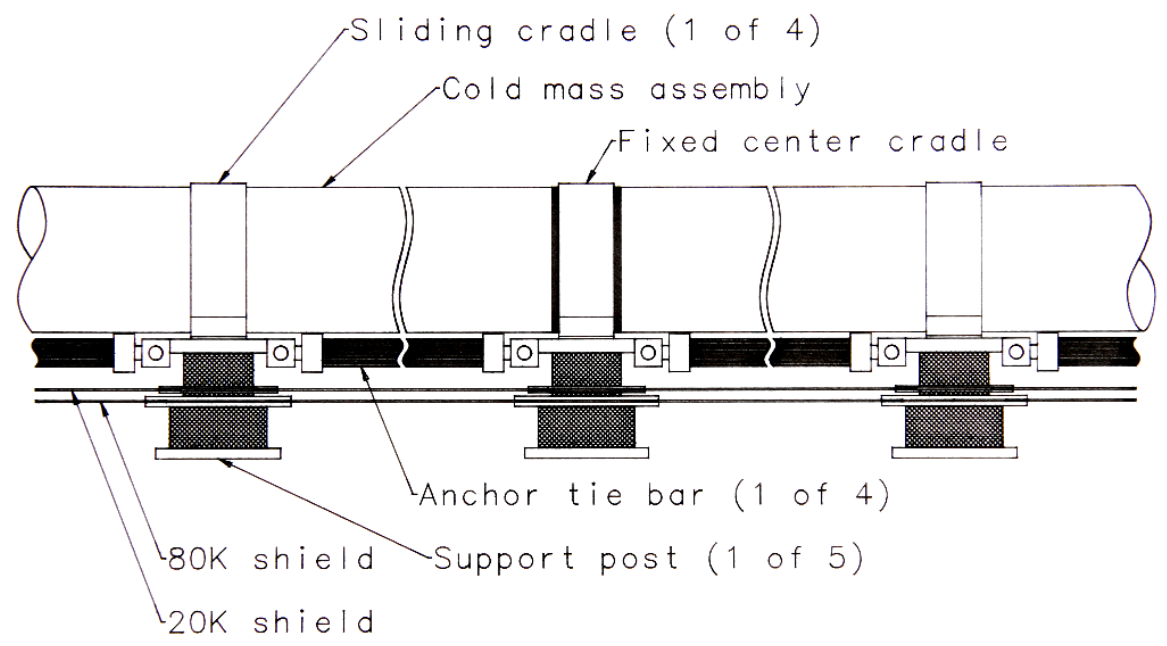

Figure 7. SSC Collider Dipole Cryostat Suspension System Components 


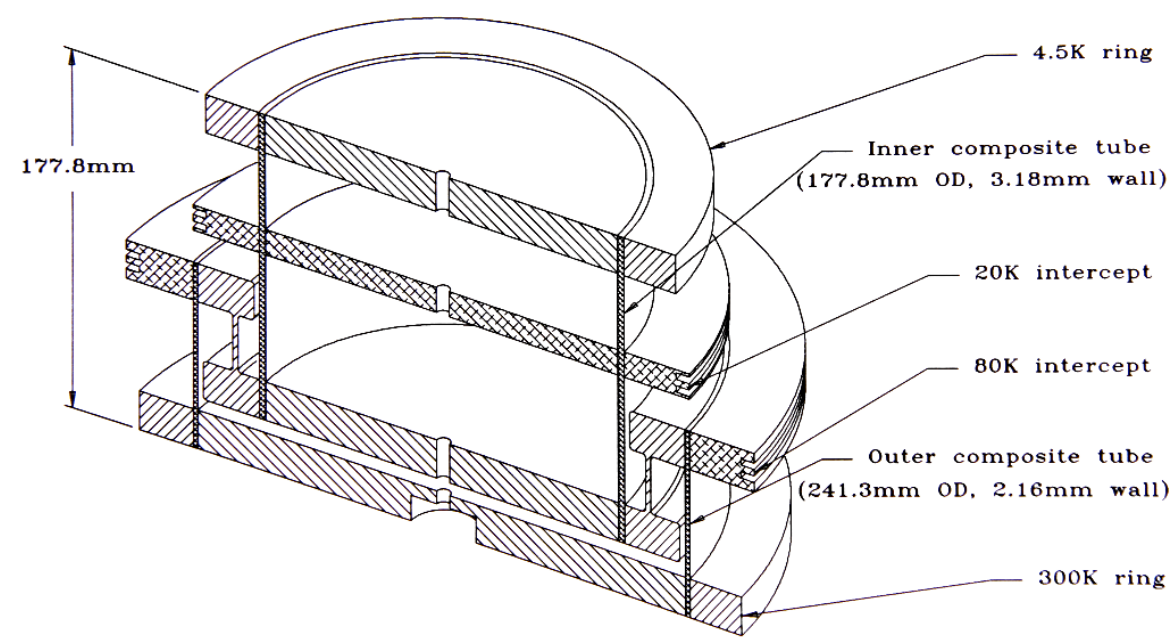

Figure 8. SSC Collider Dipole Cryostat Re-entrant Support Post

\begin{tabular}{|l|l|}
\hline \multicolumn{2}{|c|}{ Table 4. Re-entrant Support Post Design Parameters } \\
\hline Design lateral load & $32960 \mathrm{~N}$ \\
\hline Design vertical load & $22240 \mathrm{~N}$ \\
\hline Overall support height & $177.80 \mathrm{~mm}$ \\
\hline Outer composite tube & $241.30 \mathrm{~mm}$ OD, 2.16 mm wall \\
\hline & $90.55 \mathrm{~mm}$ long, glass/epoxy \\
\hline & Design stress: 132 MPa \\
\hline Inner composite tube & $177.80 \mathrm{~mm}$ OD, 3.18 mm wall \\
\hline & $150.88 \mathrm{~mm}$ long, graphite/epoxy \\
\hline & Design stress: $154 \mathrm{MPa}$ \\
\hline Theoretical lateral natural frequency & $9.41 \mathrm{~Hz}$ \\
\hline Heat load to $80 \mathrm{~K}$ & $3.133 \mathrm{~W}$ \\
\hline Heat load to 20 K & $0.492 \mathrm{~W}$ \\
\hline Heat load to $4.5 \mathrm{~K}$ & $0.033 \mathrm{~W}$ \\
\hline
\end{tabular}

Figure 9 shows the cold mass and a cradle and support post assembly. 


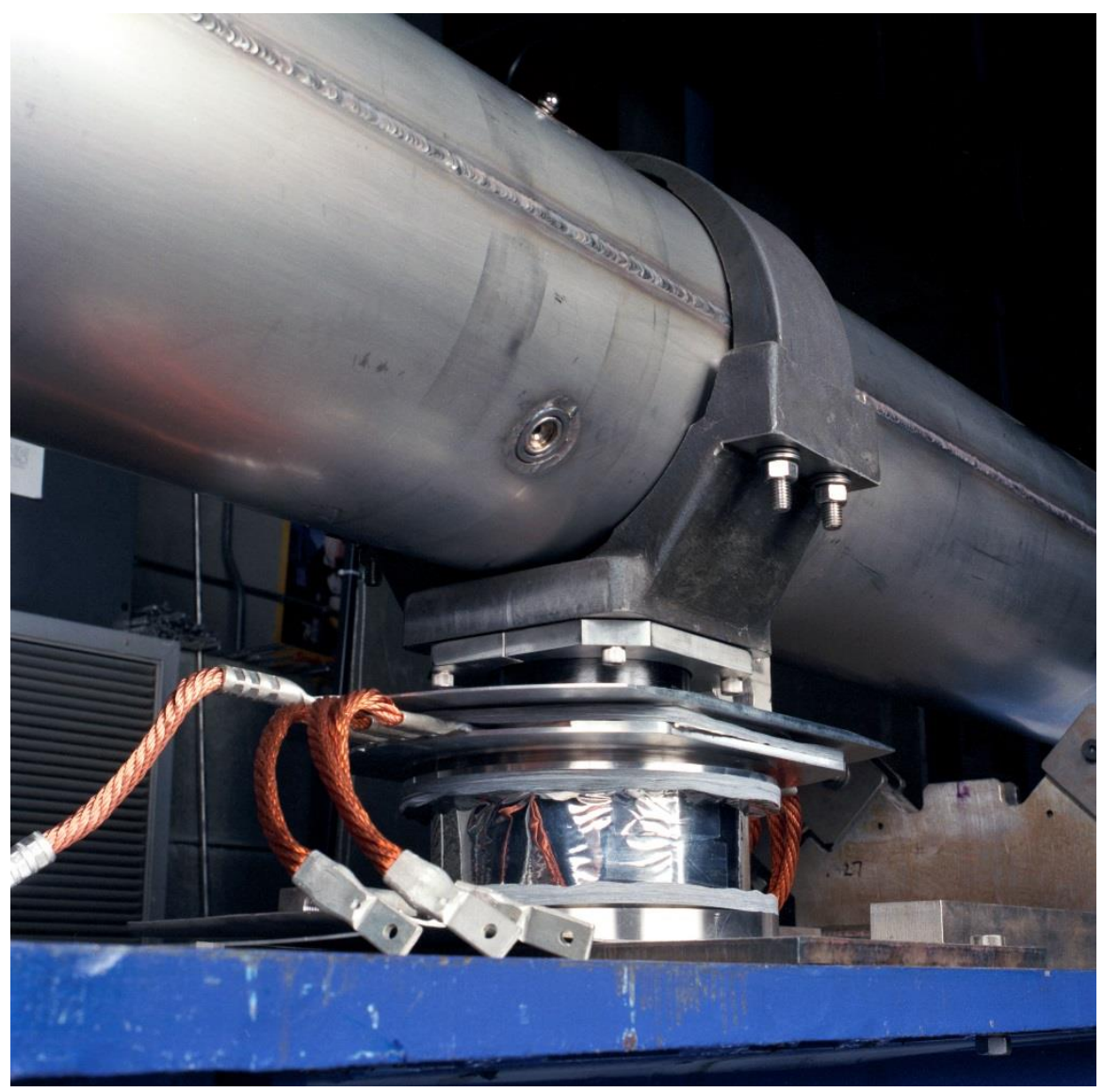

Figure 9. Cold Mass and Cradle and Support Post Assembly

\section{INTERCONNECT}

As its name implies the magnet interconnect served as the connection area between magnets at which each of the cold mass and cryostat pipes between magnets were connected. Each pipe was anchored axially at the center of the magnet which means they contracted between $25 \mathrm{~mm}$ and $32 \mathrm{~mm}$ depending on whether they were stainless steel or aluminum. The relative contraction at the interconnect was then 50 $\mathrm{mm}$ to $64 \mathrm{~mm}$, i.e. twice the single magnet value. Bellows were required on each cold mass, shield, and cryogenic pipe to allow for this expansion. All bellows were hydro-formed stainless steel. For the aluminum extrusions on the $80 \mathrm{~K}$ and $20 \mathrm{~K}$ shield pipes an aluminum to stainless steel transition joint was required for the bellows connection. Joints using diffusion bonding or brazing between these two materials had been successfully employed in $40 \mathrm{~mm}$ prototypes. Lateral instability was a concern for interconnect bellows and required the use of internal squirm protectors 
on each bellows assembly. During individual magnet testing, the bellows assemblies employed metal seals and mechanical connections, but for tunnel installation, all bellows and pipe connections were welded. [2,3]

Just like for the magnet as a whole, radiative heat transfer needed to be minimized in the interconnect area. This was accomplished by shield bridges which spanned the $80 \mathrm{~K}$ and $20 \mathrm{~K}$ shield gap between adjacent magnets. These bridges were essentially extensions to the magnet shields, modified to contain their respective bellow OD's if necessary. A sliding joint between bridge sections on adjacent magnets accommodated contraction during cooldown. Each was covered with the same MLI scheme used throughout the body of the magnet. These shield bridges also contained pressure reliefs for each shield to prevent pressure buildup within either shield in the event of an internal piping failure. The reliefs were located in the upper half of the shield sections in order to prevent liquid spills from impinging directly onto the vacuum vessel wall. Figure 10 illustrates a typical magnet interconnection. The external vacuum bellows and thermal shield bridges have been removed for clarity.

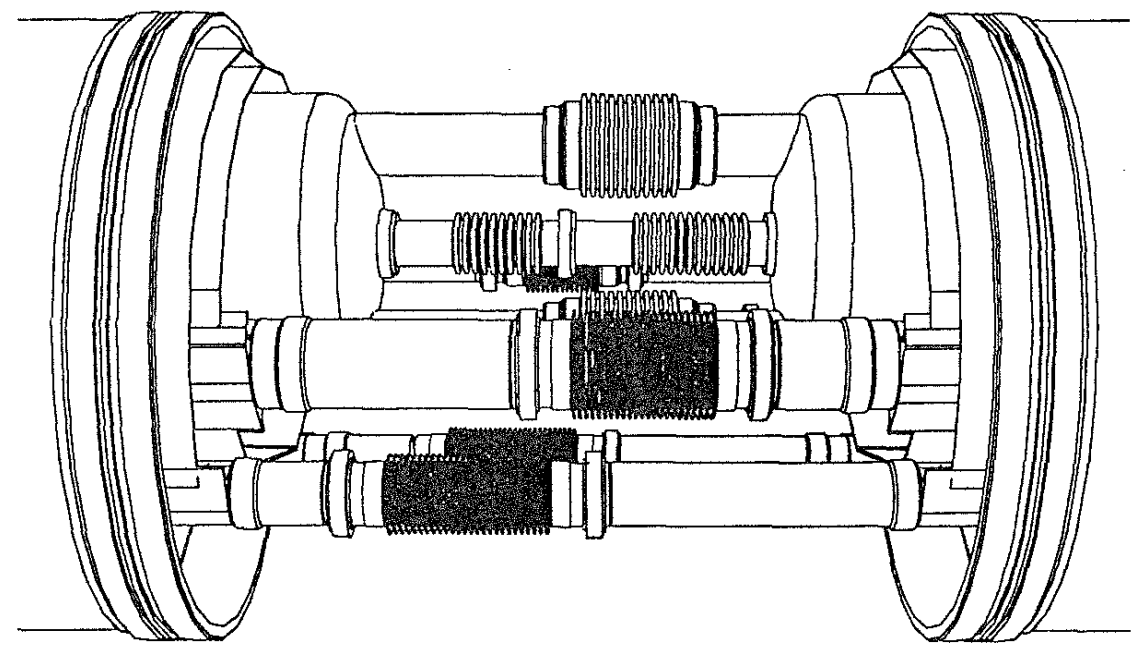

Figure 10. SSC 50mm Collider Dipole Magnet Interconnect

\section{TEST RESULTS}

Early in the $50 \mathrm{~mm}$ magnet development program a full scale thermal model was constructed and tested in a series of tests at Fermilab. The objectives of the thermal model program were to evaluate the cryostat design from a production standpoint, to gain experience in magnet handling and transportation, to monitor the transient 
thermal and structural responses of the cryostat, and to measure heat leaks to the cold mass and thermal shields. The thermal model was identical to later magnetic models except that the cold mass assembly contained a simulated collared coil assembly and the model ends were reconfigured for open cycle heat leak measurements. The model was instrumented to evaluate thermal and structural performance and included temperature sensors to monitor cooldown, warm-up, and steady state conditions and strain gauges to monitor the performance of the suspension system during onsite transit, cooldown, and operation. Construction of the thermal model utilized the same fabrication facility, assembly procedures, and components as the magnetic models. $[8,9]$

The measurements were performed in an open cycle mode with supply reservoirs at each end of the cold mass. Figure 11 shows an overview of the measurement system. The inner shield was supplied from an external dewar. The inner $20 \mathrm{~K}$ shield temperature was an operational variable which was controlled by varying its flow rate. The outer $80 \mathrm{~K}$ shield was supplied by $\mathrm{LN}_{2}$ reservoirs at each end of the measurement system. The external piping was equipped to measure flow rates of the cold mass and inner and outer shield liquid and gas streams.

After cooldown, initial filling, and stabilization of the three systems, the temperature of the inner shield was regulated to a selected test value. After regulation, temperatures and heat leaks were monitored to establish equilibrium, often taking several days. Once at equilibrium, steady state heat leak data was taken.

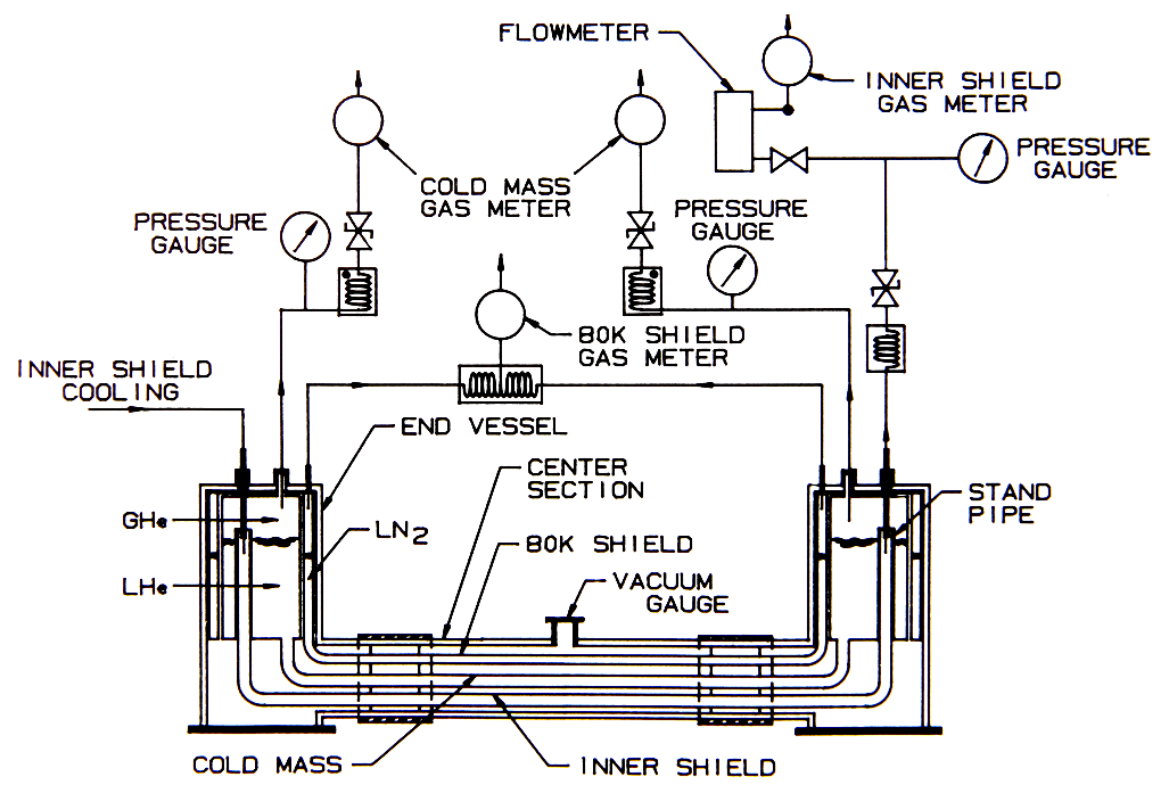


Figure 11. Thermal Model Measurement Schematic

The cold mass heat leak was determined by boil-off measurements. Since the measurement included the heat leak to the cold mass and the reservoirs at each end of the magnet, a separate measurement called the zero-magnet test was conducted using just the helium reservoirs which was then subtracted from the total system heat leak. The inner shield heat leak was computed from the shield flow rate and the temperature rise in the shield gas stream. Like the cold mass, the heat leak to the $80 \mathrm{~K}$ shield was determined using the liquid boil-off rate. As with the cold mass, the zero-magnet test results were subtracted from the total.

The measurement program took place over approximately a three month period and involved 23 data-taking runs as identified by the inner shield temperature. The following results have been screened to exclude transient periods, upset conditions, and operational problems.

Cooldown was gradual due to the open cycle nature of the operation. The cold mass was initially cooled and filled with liquid nitrogen, evacuated, and then filled with liquid helium. The total time required to cool and fill the cold mass with liquid helium was 294 hours.

The support post bending loads due to differential axial thermal contraction were low with the exception of the downstream end post which indicated a load of 4800 N. A probable cause for such a load is a non-operational cold mass slide, most likely the result of binding in the slide material itself. The support post temperature profiles agreed well with those of an identical post measured in a heat leak test facility.

Random mechanical noises occurred during cooldown and throughout the measurement program likely the result of relative motion between the cold mass, thermal shields, and support posts and the vacuum vessel due to ambient temperature variations and settling of the test pad.

The subtractive heat leak contribution of the end reservoirs was measured with the inner shield cooling tube filled with liquid helium to eliminate conduction and thermal radiation to the cold mass end to include end shine thermal radiation. Under these conditions, the shield temperature was $7.6 \mathrm{~K}$ and the measured background was $865 \mathrm{~mW}$. The background was not strongly dependent on reservoir liquid level.

Calibration heaters in the cold mass were employed to evaluate the accuracy of the measurement system. The heaters were energized with the inner shield at approximately $20 \mathrm{~K}$. The increase in the measured cold mass heat leak corresponding to heater power levels of $200 \mathrm{~mW}$ and $398 \mathrm{~mW}$ were $197 \mathrm{~mW}$ and $376 \mathrm{~mW}$, respectively. 
The cold mass heat leak at the cryostat design point with the inner shield at 20 $\mathrm{K}$, was $140 \pm 40 \mathrm{~mW}$ as compared to the predicted $128 \mathrm{~mW}$ and budgeted $300 \mathrm{~mW}$. The cold mass heat leak vs. inner shield temperature is shown in figure 12 .

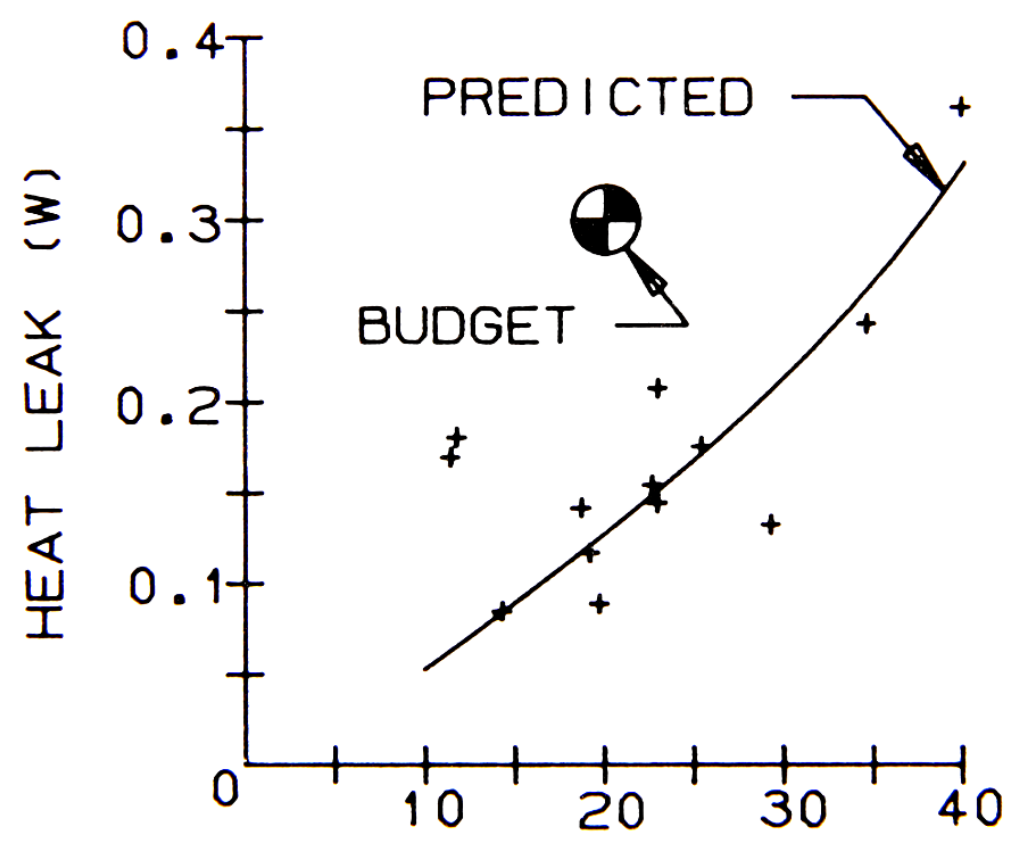

\section{INNER SHIELD TEMPERATURE ( $\mathrm{K}$ )}

Figure 12. Cold Mass Heat Leak vs. Inner Shield Temperature

Considerable differences exist between measured and predicted heat leaks at several experimental points. Factors that can contribute to these differences are as follow:

- The center section heat leak $(140 \mathrm{~mW})$ is small relative to the balance of the apparatus $(865 \mathrm{~mW})$. This unbalance amplifies end vessel effects.

- Thermal communication exists between the inner shield cooling circuit and the end vessel helium reservoirs as a result of the inner shield supply and return piping passing through the cold mass helium reservoirs. Even though the piping was insulated, transients in inner shield supply conditions could be seen to affect the reservoirs.

- Level instability (sloshing) occurred occasionally in the end vessels. The sloshing was most often associated with changes in the inner shield circuit operation. 
- The predicted sensitivity to insulating vacuum is high. At the design inner shield operating temperature of $20 \mathrm{~K}$, the residual gas (helium) conduction at $10^{-6}$ torr was $43 \mathrm{~mW}$ and at $10^{-5}$ torr was $430 \mathrm{~mW}$. The insulating vacuum at the vacuum vessel mid-span port ranged from $1.3 \times 10^{-6}$ to $2.9 \mathrm{x}$ $10^{-6}$ torr during the span of the measurements. The location and installation of the vacuum gauge was demonstrated by diagnostic measurements to inaccurately relate changes in the insulating vacuum that could correspond to changes in the outgassing rate of the mild steel vacuum vessel due to changes in ambient temperature. Consequently, vacuum was not monitored frequently during most of the data taking.

- Variations in atmospheric pressure result in temperature changes of the liquid which influence the apparent heat leak. Atmospheric pressure was not monitored frequently during most of the data taking. Where possible, the heat leak was corrected for changes of liquid temperature and pressure with time. The cold mass end to end temperature variation during operation was characteristically about $30 \mathrm{mK}$.

The inner shield heat leak at the cryostat design point was $5.0 \pm 0.4 \mathrm{~W}$ compared to the predicted $2.77 \mathrm{~W}$ and budgeted $2.5 \mathrm{~W}$. The inner shield heat leak vs inner shield temperature is given by figure 13 . 


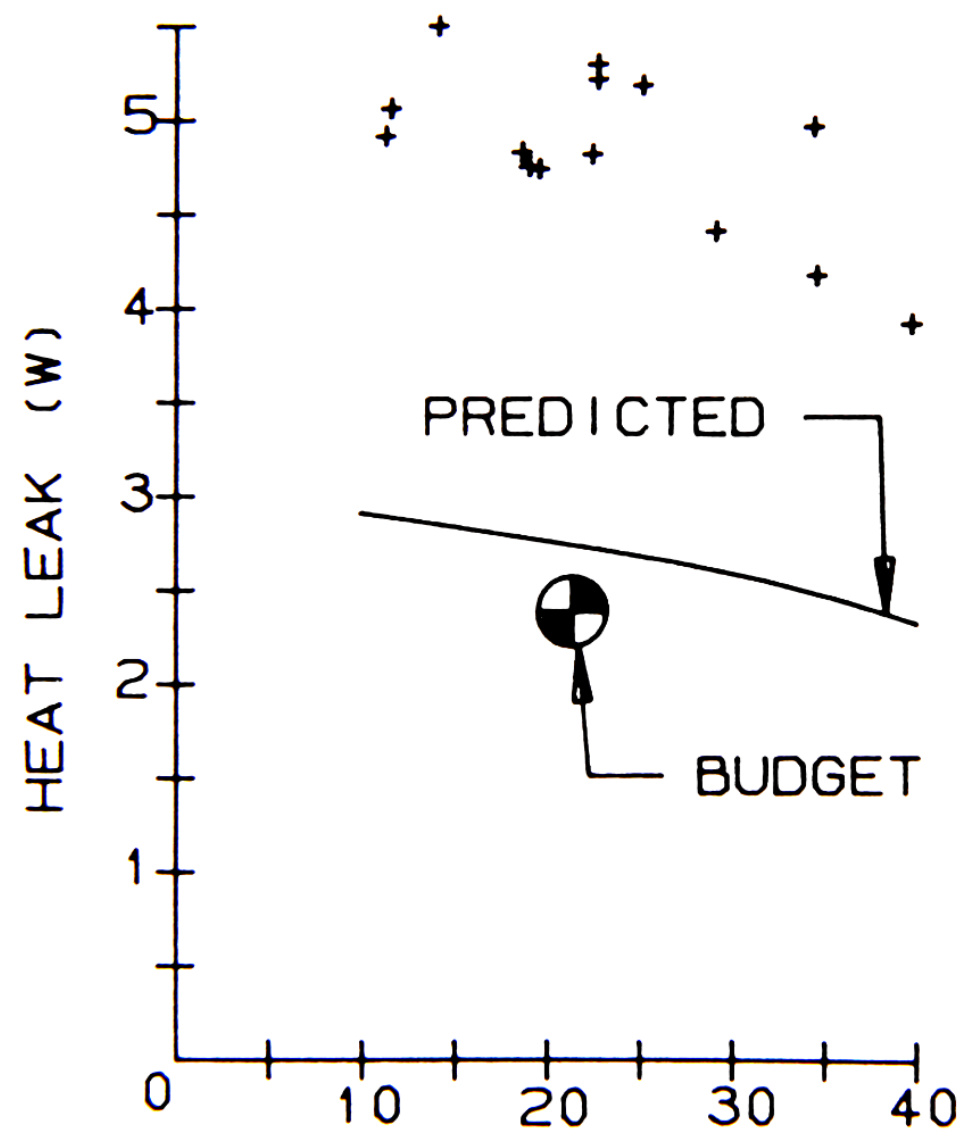

\section{INNER SHIELD TEMPERATURE (K)}

Figure 13. Inner Shield Heat Leak vs. Inner Shield Temperature

A corroboration of the inner shield heat leak measurement was provided by performing inner shield boil-off measurements during the cold mass background measurement. With the shield cooling tube filled with liquid helium, the heat leak as measured by boil-off was $5.84 \mathrm{~W}$.

The factor of two difference between measured and predicted heat leaks was felt to be due to thermal shorts between the $20 \mathrm{~K}$ and $80 \mathrm{~K}$ systems, by locally compressed insulation between the shields and by an insufficient number of layers of insulation. Shield and support temperature monitors indicate the possibility of 
shorts. An autopsy of the thermal model to investigate the existence of such thermal shorts was not conducted for programmatic reasons.

The subtractive heat leak contribution of the end reservoirs was made with the center section removed and the reservoirs connected together. The nominal background heat leak was $24 \mathrm{~W}$. The background was found to vary with level. The outer shield heat leak at the cryostat design point was $19 \pm 2 \mathrm{~W}$ compared to the predicted $23.3 \mathrm{~W}$ and the budgeted $25 \mathrm{~W}$. The outer shield heat leak vs. inner shield temperature data is given by figure 14. The less than predicted measured heat leaks were felt to be associated with the thermal shorts that are suspected exist between the inner and outer shields and their connections. The scatter in the measured heat leak was felt to be associated with the sensitivity of the insulation systems to insulating vacuum in the higher pressure ranges, i.e. greater than $10^{-4}$ torr. As noted earlier, the insulating vacuum, while not accurately measured, showed changes with ambient temperature.

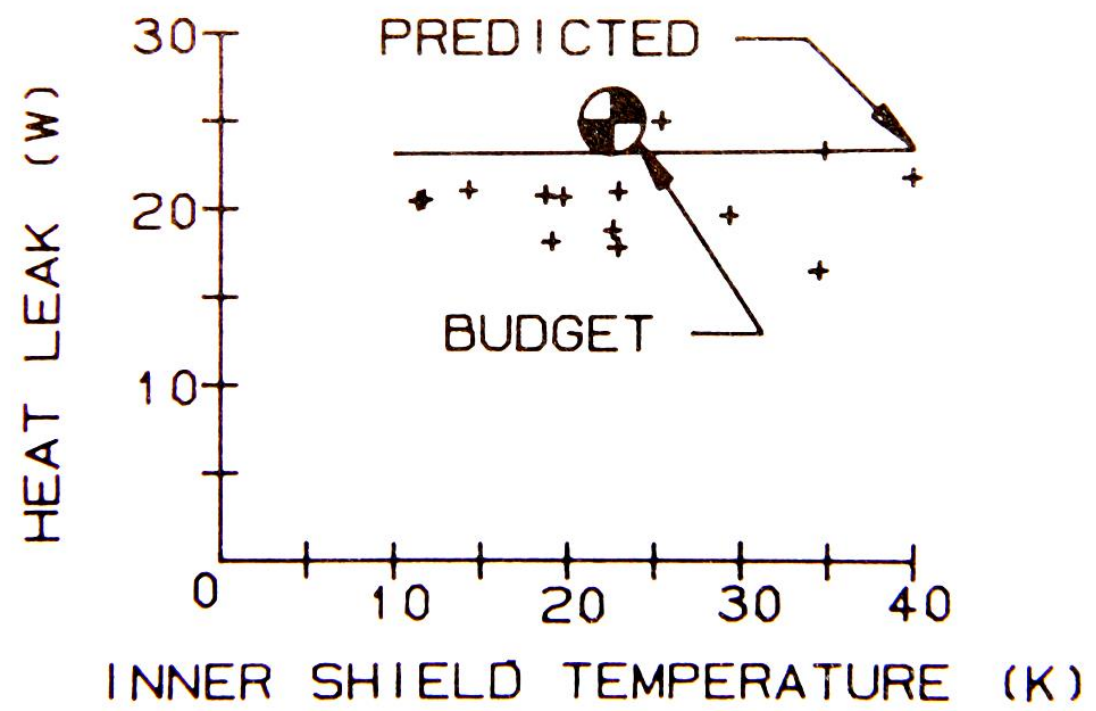

Figure 14. Outer Shield Heat Leak vs. Inner Shield Temperature

Following the completion of several prototype $40 \mathrm{~mm}$ and $50 \mathrm{~mm}$ aperture dipole magnets, similar, more extensive tests were conducted on strings of magnets at the SSC Laboratory in Waxahachie, TX. Similar discrepancies between measured, predicted, and budgeted heat leaks were documented in those tests as well, but the project was discontinued before more exhaustive tests and analyses could be conducted. 
Figure 15 shows a completed SSC collider dipole magnet on the test stand in the Fermilab Magnet Test Facility.

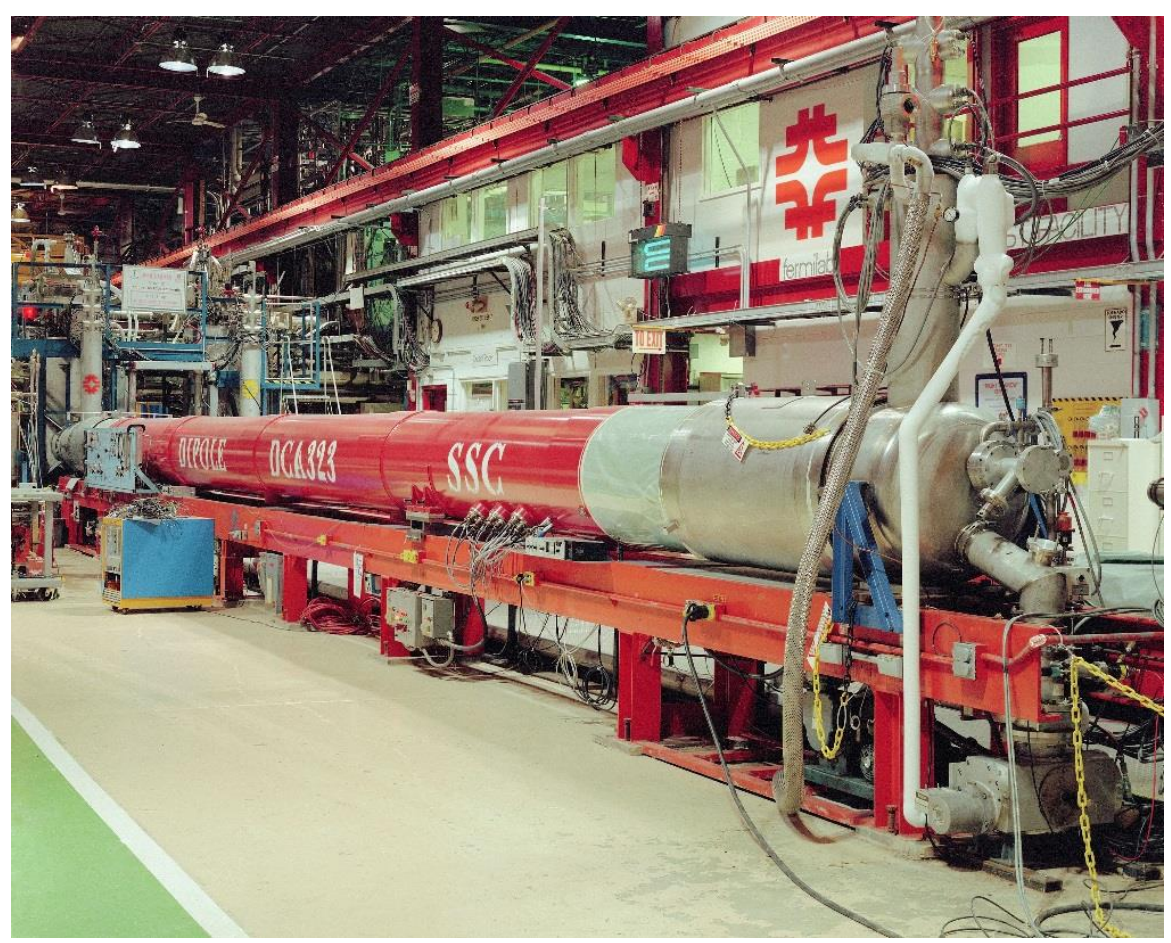

Figure 15. Complete SSC Dipole Assembly on the Fermilab Test Stand

\section{SUMMARY}

The SSC development program afforded us the opportunity to extend the design of cryostats for superconducting magnets far beyond the state of the art present at the end of the Fermilab Tevatron program. Advances in new materials technology opened up options for cryostat designers in both thermal and structural materials. Strict limits on allowable heat load forced us to develop new mechanisms for structural support and thermal shielding. The end result was a cryostat design which met the demands of the SSC and which served as the starting point for the development of other magnet systems far into the future.

It is gratifying to see projects like the LHC, TESLA, LCLS-II, and many others around the world, taking advantage of developments in multi-layer insulation tech- 
nology and fabrication techniques, thermal shield design, cryogenic support structures, and interconnect design that were made during the R\&D activities, prototyping, and production of SSC collider dipole magnets.

\section{REFERENCES}

1. SSC Central Design Group, "Superconducting Super Collider Conceptual Design", SSC-SR-2020, March 1986.

2. Nicol, T.H., "Design Development for the $50 \mathrm{~mm}$ Superconducting Super Collider Dipole Cryostat", Supercollider 3, pp. 1029-1036, Plenum Press, New York, 1991.

3. Nicol, T.H., "SSC 50 mm Collider Dipole Cryostat Design", Advances in Cryogenic Engineering, vol. 37A, pp. 525-533, Plenum Press, New York, 1991.

4. Gonczy, J.D., Boroski, Niemann, R.C., Otavka, J.G., Ruschman, M.K., Schoo, C.J., "A Blanket Design, Apparatus, and Fabrication Techniques for the Mass Production of Multilayer Insulation Blankets for the Superconducting Super Collider", Advances in Cryogenic Engineering, Vol. 35A, pp. 507-516, Plenum Press, New York, 1990.

5. Nicol, T.H., Niemann, R.C., Gonczy, J.D., "SSC Magnet Cryostat Suspension System Design", Advances in Cryogenic Engineering, Vol. 33, pp. 227-234, Plenum Press, New York, 1988.

6. Nicol, T.H., Niemann, R.C., Gonczy, J.D., “A Suspension System for Superconducting Super Collider Magnets", Proceedings of the Eleventh International Cryogenic Engineering Conference, pp. 533-538, Butterworth \& Co., Surrey, UK, 1986.

7. Larson, E.T., Carson, J.A., Nicol, T.H., Niemann, R.C., "Improved Design for a SSC Coil Assembly Suspension Connection”, Advances in Cryogenic Engineering, Vol. 33, pp. 235-241, Plenum Press, New York, 1988.

8. Niemann, R.C., Boroski, W.N., Gonczy, J.D., Nicol, T.H., Otavka, J.G., Ruschman, M.K., "SSC Dipole Magnet Cryostat Thermal Model Measurement Results", Advances in Cryogenic Engineering, Vol. 33, pp. $251-$ 258, Plenum Press, New York, 1988.

9. Gonczy, J.D., Boroski, W.N., Nicol, T.H., Niemann, R.C., Otavka, J.G., Ruschman, M.K., "Cryogenic Support Thermal Performance Measurements", Advances in Cryogenic Engineering, Vol. 33, pp. 243-250, Plenum Press, New York, 1988. 